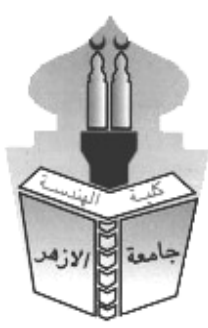

\title{
FRANCIS TURBINE PROTOTYPE TESTING AND GENERATION OF PERFORMANCE CURVES
}

\begin{abstract}
Hydroelectric power plant converts the hydraulic power in flowing water to mechanical energy. A key item of any hydro power plant is the governor. The control of the governor depends mainly on the performance curves of the turbine. Studies and measurements in the laboratory have given important information about the model and its characteristics and performance. This study concerns laboratory studies with focus on the characteristics of the Francis turbine model. The laboratory model considered in this study is a test rig set in the Fluid Mechanics laboratory at Mechanical Engineering Department manuf actured by Gilbert Gilkes and Gordon Ltd, representing a Francis turbine hydro power plant model. This manual test rig has been upgraded to control the measurements automatically. The variables measurement technology of the turbine are developed and implemented by using LabVIEW software interface.

Performance test on the test rig of a Francis turbine has been carried out in the laboratory for various gate opening of the turbine. The numerical results for the test rig were implemented to get dedicated values of the six partial coefficients of the Francis Turbine test rig that used for control studies. These partial coefficients are compared with ideal model values.
\end{abstract}

\section{Key words: Francis Turbine, Lab VIEW, Performance Curves.}

\section{INTRODUCTION}

Hydro power plays a very important role in electricity generation. During the years, hydropower technology is gradually improved. Even if the basic technology of a hydroelectric plant is the same as a hundred years ago, the control of a plant has been computerized during the last decades. This in combination with more powerful computers and software allows the construction of virtual models and simulations of hydropower systems. Models and simulation of a plant can be used in various ways such as optimization of various components or sub-systems, off-line programming, test and verification or they may function as a learning platform to increase the knowledge and understanding of how the system works [1]. In 2014, G. Aggidis and A. Židonis [2], developed a fully automated approach for hydro turbine prototype testing manufactured by Gilbert Gilkes and Gordon Ltd. The 
developed approach is for both reaction (Francis) and impulse (Pelton) turbines. The technology for fast fully automated initial testing of hydro turbines was developed and implemented on the originally manual turbine testing facility as that used in this work.

Much equipment connected to a hydroelectric system is sensitive to speed variation [3], therefore, advanced governor system and speed control of the system are necessity. The governor system design and tuning are basically based on the turbine coefficients and performance curves.

Some practical hydraulic turbine models for Francis turbines and pumped-storage hydraulic turbines are used in [4].

The models are obtained through frequency response tests depend on measured turbine coefficients. The power system frequency during transient conditions greatly depends on governor control characteristics [4].

This paper describes the automation of an originally manually controlled Francis hydropower turbine model testing facility, as shown in Fig. (1), manufactured by Gilbert Gilkes \& Gordon Ltd to enable very fast data acquisition and processing to get its characteristic curves. These curves are used to calculate the turbine coefficients at the operating point that used for control studies.

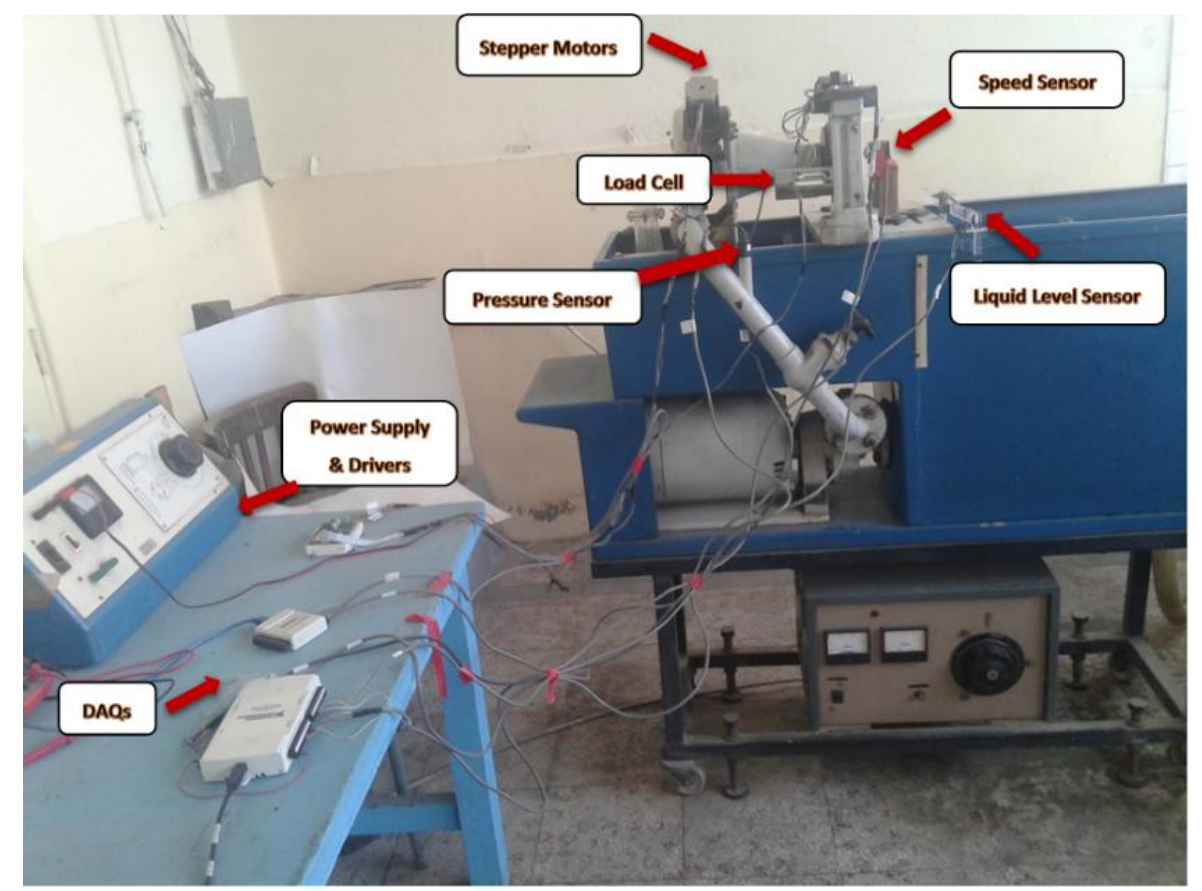

Figure 1: Francis hydropower turbine model in the Fluid Mechanics laboratory at Mechanical Engineering Department manufactured by Gilbert Gilkes and Gordon Ltd.

\section{Linearized Turbine Model}

The nonlinear characteristics of the hydro power plant models can be approximated by linear models. Linear equations are used for studies of control system stability limited to small perturbations around a stable operating point. The most common hydraulic turbine representation for system stability studies consists of a transfer function obtained by linearizing the turbine characteristic curves around an operating point [5].

The Taylor series approximation for small variations in the vicinity of an operating point in per unit gives the following equations [6 - 7],

$$
\begin{gathered}
\Delta T=\frac{\partial T}{\partial h} \Delta h+\frac{\partial T}{\partial N} \Delta N+\frac{\partial T}{\partial G} \Delta G \\
\Delta q=\frac{\partial q}{\partial h} \Delta h+\frac{\partial q}{\partial N} \Delta N+\frac{\partial q}{\partial G} \Delta G
\end{gathered}
$$


The partial derivatives of torque and flow with respect to head, rotational speed and gate position are called Turbine Coefficients. They represent the characteristics of a hydraulic turbine. They remain constant for variation near the operating point $\left(\mathrm{q}_{0}, \mathrm{~T}_{0}\right)$. Their values depend up on the initial steady state point of the turbine and they can be measured accurately by experiment. The influence of the turbine coefficients on the model accuracy is critical. These values have to be measured accurately in the field or taken from model test [5].

The partial derivative of torque with respect to gate position, $\partial \mathrm{T} / \partial \mathrm{G}$, is called Turbine Gain. Turbine Gain is a critical parameter for an accurate approximation of hydro power plants dynamics, and has to be measured precisely in the field. The partial derivatives of torque $\partial \mathrm{T} / \partial \mathrm{N}$ and flow $\partial \mathrm{q} / \partial \mathrm{N}$ with respect to rotational speed, are usually considered to be negligible [5].

For deviations around rated speed and pressure head, the turbine coefficients are deduced by the differentiation of equations (1) and (2), [8].

The partial differential equation of $\partial \mathrm{T} / \partial \mathrm{h}$ and $\partial \mathrm{q} / \partial \mathrm{h}$ in equations (1) and (2) can be involved in the following equations, [5]:

$$
\begin{aligned}
& \Delta T=\frac{\partial T}{\partial G} \Delta G+\left(\frac{T}{h}-\frac{N}{2 h} \frac{\partial T}{\partial N}\right) \Delta h+\frac{\partial T}{\partial N} \Delta N \\
& \Delta q=\frac{\partial q}{\partial G} \Delta G+\left(\frac{q}{2 h}-\frac{N}{2 h} \frac{\partial q}{\partial N}\right) \Delta h+\frac{\partial q}{\partial N} \Delta N
\end{aligned}
$$

The turbine coefficients are deduced for models neglecting the variation of the turbine efficiency [9]. The six partial derivatives in equations (3) and (4), which represent the nonlinear characteristic of the turbine, can be measured and drawn experimentally from the basic model test data for the actual turbine. The water head $\mathbf{h}$ and turbine speed $\mathbf{N}$ keep almost rated values, so that they can be regarded as rated values. Torque $\mathbf{T}$ and discharge $\mathbf{q}$ are functions of a gate position $\mathbf{G}$ and a turbine speed $\mathbf{N}_{\mathbf{u}}$ [5].

Some proposed values of these constants from turbine characteristic equations are available from literature (see Table 1) [8], [9]. This table includes also the standard or classical turbine coefficients values for an ideal lossless turbine [13].

Table 1: Turbine Coefficients $[8,9,13]$

\begin{tabular}{c|c|c|c}
\hline Partial Derivatives & $\begin{array}{c}\text { Reference } \\
{[\mathbf{8}]}\end{array}$ & $\begin{array}{c}\text { Reference } \\
{[\mathbf{9}]}\end{array}$ & $\begin{array}{c}\text { Classical Values } \\
{[\mathbf{1 3}]}\end{array}$ \\
\hline$\partial \mathbf{q} / \partial \mathbf{h}$ & $0.50 \mathrm{G}_{0}$ & $\frac{G}{\sqrt{2 h}}$ & 0.5 \\
\hline$\partial \mathbf{q} / \partial \mathbf{N}$ & 0 & 0 & 0 \\
\hline$\partial \mathbf{q} / \partial \mathbf{G}$ & 1 & $\sqrt{h}$ & 1 \\
\hline$\partial \mathbf{T} / \partial \mathbf{h}$ & $1.50 \eta \mathrm{G}_{0}$ & $A_{t}\left(\frac{3}{2} G \sqrt{h}-q_{N L}\right)$ & 1.5 \\
\hline$\partial \mathbf{T} / \partial \mathbf{N}$ & 0 & $-D * G$ & 0 \\
\hline$\partial \mathbf{T} / \partial \mathbf{G}$ & $\eta$ & $A_{t} h^{3 / 2}-D(\Delta \bar{\omega}-1)$ & 1 \\
\hline
\end{tabular}

\section{Experimental Test Rig}


The experimental set up used was originally designed and manufactured in 1970s as an academic teaching tool. This turbine tester can be treated as a small-scale model of a real hydropower station which has all the corresponding features as the real power plant would have as shown in Fig. (1). In a closed loop, a centrifugal pump powered by a motor provides the flow and the pressure, which is considered as the pressure head of the turbine, and therefore they can be treated as the gross pressure head and the river flow in the real power station. The tester has a Francis turbine which is coupled to a Prony brake load to simulate the load applied by the generator [2]. Table (2) gives the specifications of the model used.

Table 2: Francis Turbine test rig Specifications

\begin{tabular}{c|c}
\hline Item & Value \\
\hline Rated Power & $300 \mathrm{~W}$ \\
\hline Rated Head & $12.8 \mathrm{~m}$ \\
\hline Rated Speed & $2300 \mathrm{rpm}$ \\
\hline Rated Flow Rate & $0.00385 \mathrm{~m}^{3} / \mathrm{s}$ \\
\hline Penstock Length & $0.48 \mathrm{~m}$ \\
\hline Penstock Diameter & $0.0385 \mathrm{~m}$ \\
\hline Penstock Cross Sectional Area & $0.002328 \mathrm{~m}^{2}$ \\
\hline
\end{tabular}

\subsection{Parameters Measurements}

The measured parameters in this research are:

1- Turbine pressure head.

2- Turbine flow rate.

3- Turbine speed.

4- Turbine torque.

5- Guide vanes position.

Four electronic sensors in addition to two stepper motors are installed on the turbine tester and connected to two data acquisition card made by National Instruments NI USB (6218 and 6008) to allow instant acquisition of all variables required. Table (3) shows the sensors used for measurements. The previous sensors are installed on the turbine tester and connected to a data acquisition card (NI USB-6218). Guide vanes and brake stepper motors are installed and connected to the other data acquisition card (NI USB-6008) to allow instant acquisition of all readings required.

Turbine speed (rpm) is measured by a rotary encoder while a fluid level sensor was used to measure the water level, $\mathbf{Z}$ before the weir to calculate both flow rate and the pressure head of the turbine.

The flow is measured by using a $90^{\circ}$ triangular profile weir, [10-11] measuring the head $\mathrm{Z}$ on the weir from the following equation:

$$
Q_{f}=\frac{8}{15} C_{d} \sqrt{2 g} \tan \left(\frac{90^{\circ}}{2}\right) Z^{2.5}
$$

Where $\mathbf{C}_{\mathbf{d}}$ is coefficient of discharge taken to be equal 0.6.

Load cell is used for measuring power of a shaft by using what is called Prony Brake. A Prony brake is a device that absorbs and measures the power output of a prime mover. Typical schematics of the brake arm used to apply the torque load on the turbine shaft is shown in Fig. (2). A rotating disc is mounted on the shaft to increase the diameter of the shaft at the place where the load is applied. The brake arm is causing friction on the surface of the rotating disc. It is done by pushing two selflubricating pads mounted on the brake arm to the disc. The brake force is adjusted by tightening the control nut which is directly coupled to the stepper motor and hence driven by it. The Double-ended shear beam load cell measures the load $\mathbf{F}$ applied by the brake arm which is multiplied by the brake arm radius $\mathbf{r}$ to give the torque applied on the turbine shaft [2]:

$$
T=F r
$$

where, $\mathbf{F}$ is the force $[\mathbf{N}]$ applied on the load cell by the brake arm, and $\mathbf{r}$ is the brake arm radius [m] 


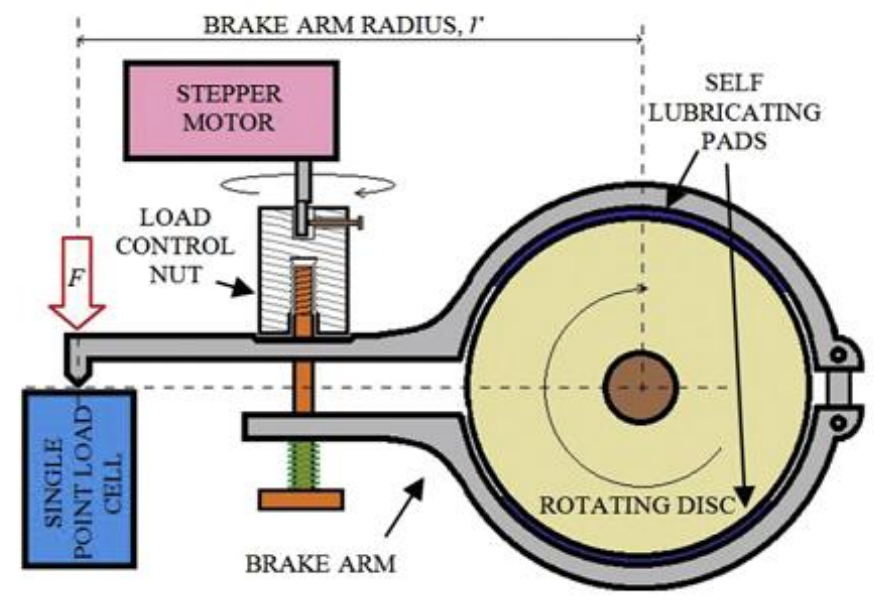

Figure 2: Schematic of the Prony Brake used for torque measurement quoted from [2]

Calibration of the load cell has been done by using standard weights to get the indicated volt values from the load cell and then getting the calibration curve and calibration equation.

Also, Calibration for other sensors are made before getting variable measurements of the turbine.

Table 3: Details of sensors used for measurements

\begin{tabular}{c|c}
\hline Sensor & Measured Variable \\
\hline Liquid Level Sensor & Turbine Head, Flow Rate \\
\hline Rotary Encoder & Turbine Speed \\
\hline Load Cell & Turbine Torque \\
\hline Stepper Motor & Brake, Guide Vanes Positions \\
\hline
\end{tabular}

To be able to study the experimental prototype variables, the sensors are connected via a PC to a LabVIEW software interface. The LabVIEW interface facilitates all the control sequences and has a graphical user interface. An embedded application is built in LabVIEW to acquire and process date during experiments. Sub Visual Instruments for Francis turbine variables are implemented and tested [3]. Figure (3) shows the sensors interface to the computer by LabVIEW software.

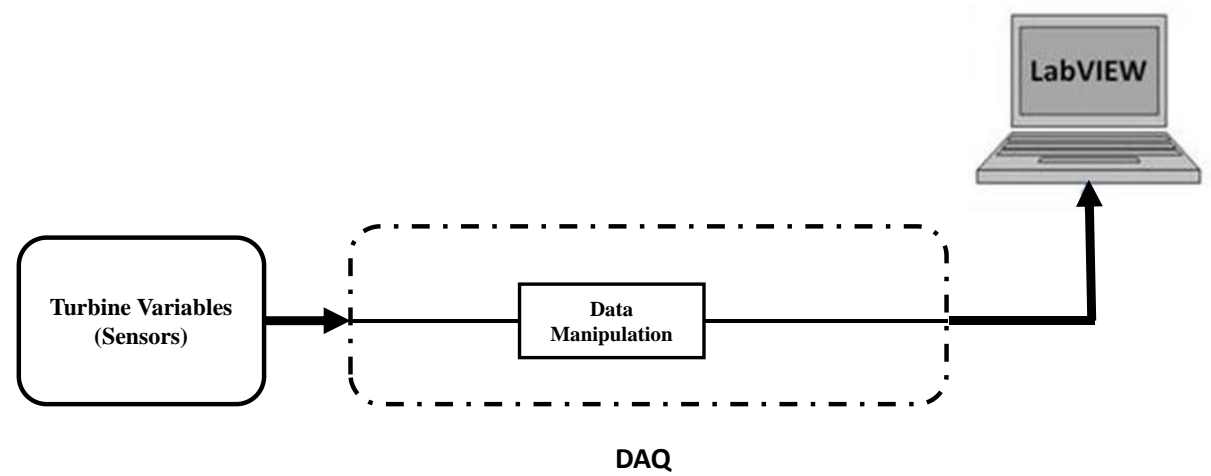

Figure 3: Schematic diagram of variables measurement and acquiring to PC through LabVIEW.

The LabVIEW software is included with the data acquisition and can be used to set up the test, acquire and archive measurement data, and perform real-time display and analyze the incoming measurements. Figure (4) Shows the data acquisition used while Fig. (5) Shows software front panel and sample of the data output graph. 


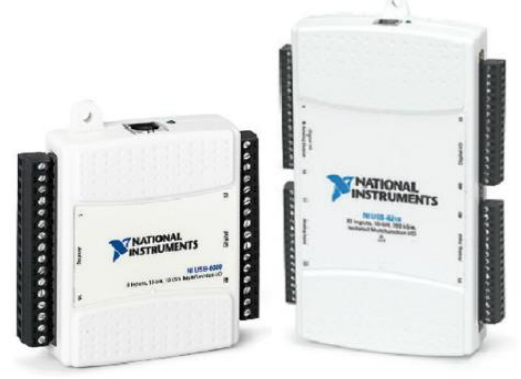

Figure 4: A photograph of the data acquisition NI- 6008 \& NI- 6218
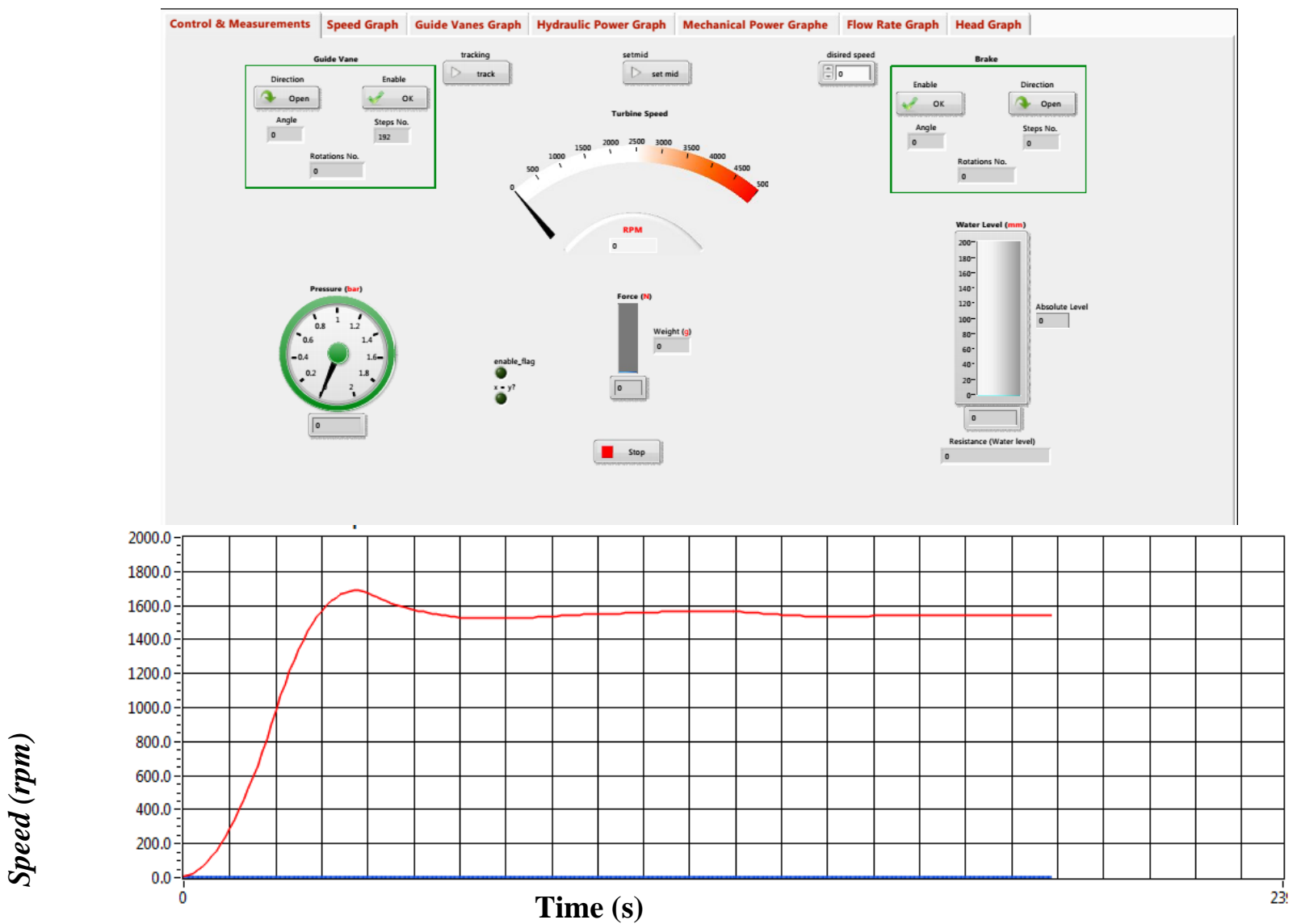

Figure 5: Software Front Panel and its output data sample

\section{Results}

\subsection{Turbine characteristic curves}

The numerical results for the test rig were implemented to get dedicated values of the six partial coefficients of the Francis Turbine test rig. Performance test on this test rig has been carried out in the laboratory for various gate opening of the turbine. The parameters have been expressed in the term of unit quantities to normalize system representation. Compared to the use of physical units, the per unit format offers computational simplicity by eliminating units and expressing the system quantities as dimensionless ratios [14]. The base values are chosen so that the principal variables will be equal to one per unit under rated conditions.

The characteristic curves obtained are at constant head curves or main characteristic curves. 
For constant head curves: Maintaining a constant head, the speed of the turbine is varied by admitting different rates of flow by adjusting the percentage of gate opening. From each test the per unit Torque $\mathbf{T}$, the per unit speed $\mathbf{N}$, the per unit discharge $\mathbf{q}$ are determined. The characteristic curves drawn are:

a) Per unit Torque vs. per unit speed.

b) Per unit Discharge vs. per unit speed.

Experimental results obtained at four wicket gate openings from minimum to full gate opening of the Francis turbine. Figure (6) shows Turbine torque $\mathbf{T}$ vs. turbine speed $\mathbf{N}$ while Fig. (7) shows Discharge $\mathbf{q}$ vs. turbine speed $\mathbf{N}$. These data are measured when system is at steady state.

Figure (6) indicates that the unique maximum value of T exists at $\mathbf{N}=0$ for all the openings of the wicket gates. Further, maximum value of $\mathrm{T}$ has been obtained at full opening of the wicket gate though there is marginal change in $\mathbf{T}$ for $50 \%, 75 \%$ and $25 \%$ opening of the wicket gates.

Fig. (7) shows the variation of per unit discharge $\mathbf{q}$ with $\mathbf{N}$. The figure depicts that the discharge increases with the gate opening and with the decrease in $\mathbf{N}$. The phenomenon is similar as expected.

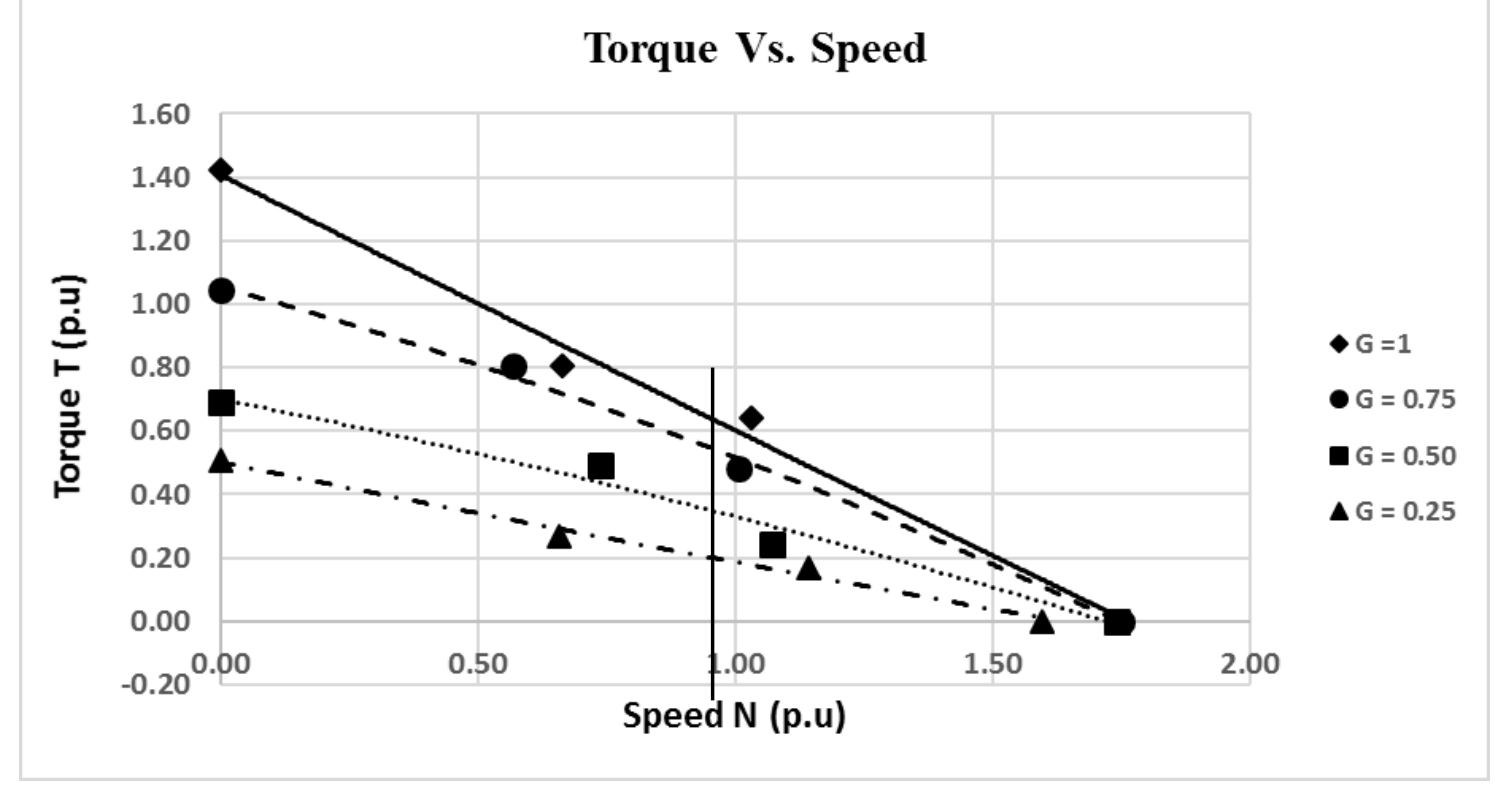

Figure 6: Turbine torque T vs. turbine speed $\mathbf{N}$

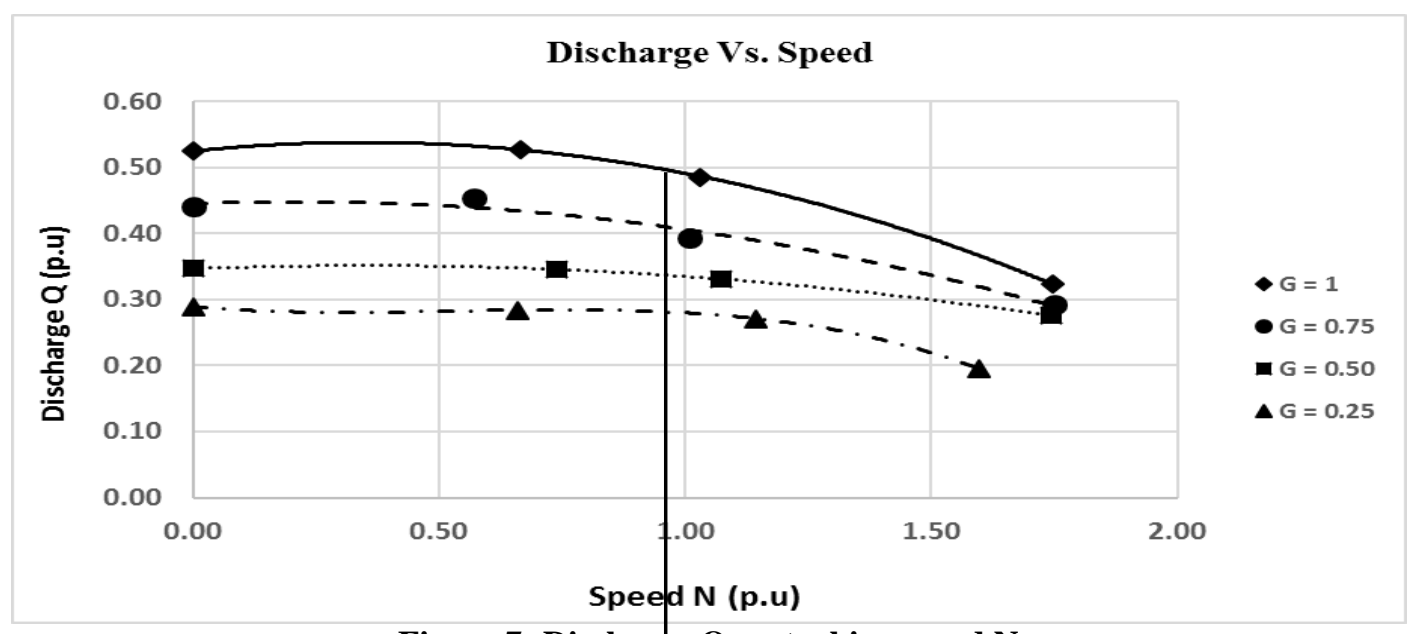

Figure 7: Discharłe $Q$ vs. turbine speed $N$

As shown in figures (6) and (7), there are four points obtained for each gate position at different speed values to get the turbine characteristic curves. We obtain average values for each point. An example of the format of the acquired numerical data is shown in Fig. (8). These data and average values shown in figure (8) are obtained at full opening guide vanes at aimed speed equal $2300 \mathrm{rpm}$. 


\begin{tabular}{|c|c|c|c|c|c|c|c|c|}
\hline $\mathbf{N}$ & No. & Speed & $\mathbf{T}$ & No. & Torque & Q & No. & Discharge \\
\hline 2370 & & & 1.674 & & & 1869 & & \\
\hline & 1 & 2595.8 & & 1 & 1.7 & & 1 & 1928.1 \\
\hline & 2 & 2562.9 & & 2 & 1.7 & & 2 & 1928.7 \\
\hline & 3 & 2527.2 & & 3 & 1.7 & & 3 & 1934.4 \\
\hline & 4 & 2490.6 & & 4 & 1.7 & & 4 & 1926.4 \\
\hline & 5 & 2453.5 & & 5 & 1.9 & & 5 & 1912.2 \\
\hline & 6 & 2416.3 & & 6 & 1.9 & & 6 & 1916.2 \\
\hline & 7 & 2379.3 & & 7 & 1.9 & & 7 & 1916.3 \\
\hline & 8 & 2343.7 & & 8 & 1.4 & & 8 & 1903.6 \\
\hline & 9 & 2309.5 & & 9 & 1.7 & & 9 & 1892.9 \\
\hline & 10 & 2276.2 & & 10 & 2.2 & & 10 & 1871.8 \\
\hline & 11 & 2243.9 & & 11 & 1.6 & & 11 & 1852.7 \\
\hline & 12 & 2214.6 & & 12 & 1.7 & & 12 & 1856.1 \\
\hline & 13 & 2188.6 & & 13 & 1.7 & & 13 & 1858.3 \\
\hline & 14 & 2165.9 & & 14 & 1.9 & & 14 & 1869.2 \\
\hline
\end{tabular}

Figure 8: An example of the format of the acquired numerical data

\subsection{Turbine Coefficients}

Further based on the results obtained, the six partial coefficients in equations (1), (2) and table (1) can be computed using Fig. (6) and Fig. (7) that were drawn from the basic prototype test data for the hydraulic turbine shown in Fig. (1).

To get $\partial \mathrm{T} / \partial \mathrm{N}$ and $\partial \mathrm{q} / \partial \mathrm{N}, 2^{\text {nd }}$ degree polynomials are fitted to every single curve of the turbine characteristic curves in Fig. (6) and Fig. (7). Then, the fitting polynomial equations are differentiated to get the partial derivatives of torque $\partial \mathrm{T} / \partial \mathrm{N}$ and flow $\partial \mathrm{q} / \partial \mathrm{N}$ at each four guide vanes position at $\mathrm{N}=$ 1 p.u.

Similarly, the partial derivatives of torque $\partial \mathrm{T} / \partial \mathrm{G}$ and flow $\partial \mathrm{q} / \partial \mathrm{G}$ are obtained by getting the relationship between both torque $\mathbf{T}$ and discharge $\mathbf{q}$ against guide vanes positions $\mathbf{G}$. These curves are fitted with $2^{\text {nd }}$ degree polynomials and obtained at $\mathrm{N}=1 \mathrm{p}$.u. Then, the fitting polynomial equations are differentiated to get the partial derivatives of torque $\partial \mathrm{T} / \partial \mathrm{G}$ and flow $\partial \mathrm{q} / \partial \mathrm{G}$ at $\mathrm{N}=1$ p.u

Finally, the partial derivatives of torque $\partial \mathrm{T} / \partial \mathrm{h}$ and flow $\partial \mathrm{q} / \partial \mathrm{h}$ in equations (3) and (4) depend on the partial derivatives of torque $\partial \mathrm{T} / \partial \mathrm{N}$ and flow $\partial \mathrm{q} / \partial \mathrm{N}$ respectively.

Figure (9) shows the values of the six partial coefficient in equation (1) and (2) against the gate positions at $\mathrm{N}=1$ p.u. These coefficients obtained after $2^{\text {th }}$ order polynomials are fitted on every single curve. In equations (3) and (4), the water head and turbine speed keep almost rated values, so that they can be regarded as rated values. Torque and discharge are the variables of a gate position and a turbine speed. Therefore, the six partial coefficients in equations (3) and (4) change according to a gate position. 


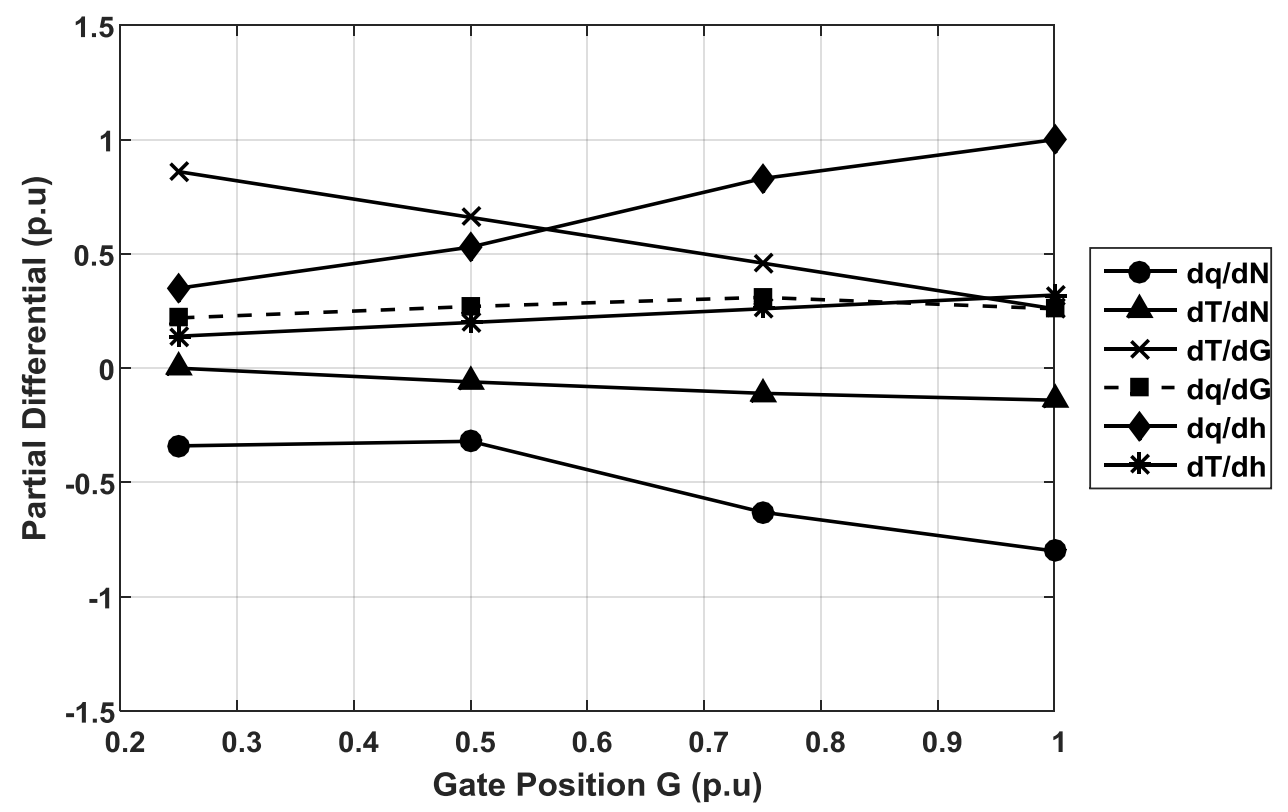

Figure 9: Partial differential values in table (4) for Francis turbine test rig.

Standard or classical values for an ideal lossless turbine [13] and three different linearized values of the turbine coefficients are shown in the Table (4) [12]. It also includes the parameters values of the studied turbine that were deduced experimentally from the characteristic curve of the turbine Hill Chart of the Francis turbine test rig at rated values with speed $\mathrm{N}=1$ p.u and at about efficiency $\eta=70 \%$.

Table 4: Turbine Coefficient Values

\begin{tabular}{|c|c|c|c|c|c|}
\hline \multirow{2}{*}{$\begin{array}{c}\text { Partial } \\
\text { Derivatives }\end{array}$} & \multicolumn{3}{|c|}{ Generator Operating Conditions } & \multirow{2}{*}{$\begin{array}{c}\text { Classical } \\
\text { values [13] }\end{array}$} & \multirow{2}{*}{$\begin{array}{c}\text { Exp.Test Rig } \\
\text { Results } \\
(300 W) \\
\end{array}$} \\
\hline & 22.5(MW) & 84.3(MW) & $112(\mathrm{MW})$ & & \\
\hline$\partial \mathrm{q} / \partial \mathrm{h}$ & 0.06 & 0.20 & 0.24 & 0.50 & 0.227 \\
\hline$\partial \mathrm{q} / \partial \mathrm{N}$ & 0.13 & 0.38 & 0.62 & 0 & -0.07 \\
\hline$\partial \mathrm{q} / \partial \mathrm{G}$ & 0.80 & 0.40 & 0.38 & 1 & 0.265 \\
\hline$\partial \mathrm{T} / \partial \mathrm{h}$ & 0.40 & 1.20 & 1.50 & 1.50 & 0.68 \\
\hline$\partial \mathrm{T} / \partial \mathrm{N}$ & -0.39 & -0.86 & -0.75 & 0 & -0.519 \\
\hline$\partial \mathrm{T} / \partial \mathrm{G}$ & 0.88 & 0.90 & 0.34 & 1 & 0.56 \\
\hline
\end{tabular}

\section{CONCLUSION}

The output data of the present study carried out on a France turbine model is important for further studies of turbine system stability and control. These data are focused on the characteristics and performance of the turbine, from which the calculation of some turbine important coefficients is possible. The values of the model system coefficients have enough accuracy for the farther turbine stability studied. These coefficients generally also help in the study and design for hence enhancing the development of the controller.

It is also generally concluded that the output of this work on a turbine model can be used in physical modeling of components found in a Francis turbine (turbine, Penstock, and governor), and simulation, which depends basically on the turbine coefficients values evaluated experimentally in this paper. Analyses and tuning of the controller and enhance the control system and turbine performance and the dynamic response of governing system to load disturbances on the turbine can therefore be achieved 
and evaluated. By this way we postulate the advanced and modern control algorithms could be selected to improve the robustness properties of the hydropower model based on the capability of determining these coefficients.

\section{NOMENCLATURE}

$\begin{array}{clc}\underset{A}{C_{d}} & \text { Penstock Cross Section Area } & \mathrm{m}^{2} \\ g & \text { Coefficient of Discharge } & \mathrm{m} / \mathrm{s}^{2} \\ G & \text { Gravitational acceleration } & \% \\ h & \text { Guide Vanes Position } & \mathrm{m} \\ L & \text { Turbine head } & \mathrm{m} \\ N & \text { Penstock Length } & \mathrm{rpm} \\ \mathrm{N}_{\mathrm{u}} & \text { Turbine Speed } & \mathrm{rpm} \\ q & \text { Unit Speed } & \mathrm{m} / \mathrm{s} \\ \mathrm{T} & \text { Discharge } & \mathrm{N} . \mathrm{m} \\ \Delta \omega & \text { Mechanical Torque } & \mathrm{rpm} \\ \mathrm{z} & \text { Turbine/Generator speed deviation } & \mathrm{m} \\ \mathrm{Q}_{\mathrm{f}} & \text { Liquid Level measurement } & \mathrm{m} / \mathrm{s} \\ \eta & \text { Flow Rate measurement } & \%\end{array}$

\section{REFERENCES:}

[1] H. Goyal, T. S. Bhatti, and D. P. Kothari, "A novel technique proposed for automatic control of small hydro power plants," Int. J. Global Energy Issues, vol. 24, 2005.

[2] G. A. Aggidis and A. Židonis, "Hydro turbine prototype testing and generation of performance curves: Fully automated approach," Renew. Energy, vol. 71, pp. 433-441, 2014.

[3] A. Karlsson and T. Indberg, "Development of a test bench for dynamic hydroelectric plant control," MSc, Department of Signals and Systems, Chalmers University of Technology, Sweden, 2011.

[4] A. Izena, H. Kihara, T. Shimojo, K. Hirayama, N. Furukawa, T. Kageyama, T. Goto, and C. Okamura "Practical hydraulic turbine model," IEEE Power Eng. Soc. Gen. Meet., pp. 1-7, 2006.

[5] L. Tenorio and T. Toftevaag, "Hydro Turbine and Governor Modelling," MSc, Department of Electric Power Engineering, Norwegian University of Science and Technology, Norway, 2010.

[6] Y. Jiandong, B. Haiyan, and F. Liang. "Study on Nonlinear Dynamical Model and Control Strategy of Transient Process in Hydropower Station with Francis Turbine". in Power and Energy Engineering Conference, APPEEC 2009. Asia-Pacific. 2009.

[7] J. Fraile, J. Perez, I. Sarasua, and J. Wilhelmiand. "Speed Optimisation Module of a Hydraulic Francis turbine based on Artificial Neural Networks. Application to the Dynamic Analysis and Control of an Adjustable Speed Hydro Plant. in Neural Networks", IJCNN '06. International Joint Conference on. 2006.

[8] D.N. Konidaris, and J.A. Tegopoulos, "Investigation of oscillatory problems of hydraulic generating units equipped with Francis turbines". Energy Conversion, IEEE Transactions on, 1997. 12(4): p. 419-425.

[9] B. Strah, O. Kuljaca and Z. Vukic, "Speed and Active Power Control of Hydro Turbine Unit, IEEE Trans. on Energy Conversion", vol. 20, no. 2, Jun. 2005, Page(s): 424-434

[10] W. Boiten, "Flow-measuring structures". Wageningen: Wageningen Agricultural University, Netherlands; Volume 4, Issue 1, Pages 17-24, January 1993.

[11] C.F. Cusick, "open channel flow measurement". Sewage and industrial wastes, Water Environment Federation; Vol. 29, No. 9 (Sep., 1957), pp. 1078-1082.

[12] J. Jiang, "Design of an optimal robust governor for hydraulic turbine generating units". Energy Conversion, IEEE Transactions on, 1995. 10(1): p. 188-194.

[13] P. Kundur, 'Power System Stability and Control' in , New York: McGraw-Hill, 1994.

[14] G. A. Munoz, S. P. Mansoor, and D. I. Jones, Modelling and Controlling Hydropower Plants, Advances in Industrial Control, Springer, London, 2013. 